\title{
The Theory-Practice Relationship in ESL and the "Art of the Eclectic"
}

David Piper

The theory-practice relationship in ESL, as in other curriculum areas, is a matter of continual concern. This paper reviews some of the central issues and problems relating to the interpretation of theory and research for ESL practice. The discussion focuses on four main areas: 1) the relationship between theoretical and practical knowledge, 2) the temporary nature of theories, 3 ) the status of theoretical constructs, and 4) the multiple interpretability of theory and research. Fol- lowing insistence upon the "art of the eclectic" in curriculum deliberation by Schwab $(1970,1971,1973,1983)$, an attempt is made to distinguish between principled and unprincipled interpretations of eclecticism. The main conclusion of the paper is that the relationship between theory and practice must be an indirect one, one which therefore depends upon the skills of teachers as classroom researchers and deliberators about curriculum.

In light of the growing interest in various kinds of research into second language learning and the development of many models and theories over the last two decades, together with an equally strong development of interest by publishers in making the results of such explorations marketable, analysis of the relationship between theory and practice continues to be of concern. The following are typical comments from ESL teachers or student teachers, and they reflect the tension between what ESL teachers think they should do and what actually goes on in classrooms: "I know I should always be using communicative methods, but my students always seem to want some drills, and sometimes they even seem to learn something from them!"; "I didn't think this activity would work but it did ..." (or the converse: "I really thought this activity would work, but all they wanted was more of what I'd been doing the day before.")

Both researchers and teachers search for consistent patterns in learning behaviour, but the question of what the relationship is between theoretical and practical consistencies is a complex one requiring some understanding of the nature of theories and of practical decision-making in general. There are several underlying issues and problems relating to the general question of applying theory to practice. The question can be broken down into several component parts. Some of the most predominant foundational problems are: first, that of relating theoretical and practical knowl- 
edge; second, that of the temporariness of most theories; third, that of the uncertain status of many "constructs" theorists present us with; and fourth, that concerning the many ways in which theory and research can be interpreted. These four categories by no means cover all areas relevant to an exhaustive analysis, but a short overview of each of them serves to clarify some of the matters that need to be taken into account when we apply theory and research to ESL practice.

\section{The relationship between theoretical and practical knowledge.}

A central question here is whether or not any theory within the domain of ESL, whether it be a theory of language structure or of cross-cultural interaction, is in principle directly interpretable for practice. To illustrate the problem we need only to remind ourselves of a relevant case in point: the fact that over the past two decades of stimulating work on generative grammar, very little of this theory has been readily interpretable for classroom practice. But is this difficulty in interpreting theory for practice due to any particular theory (such as transformational grammar) or does it result from more general differences between the nature of the theoretical and the practical per se?

While it appears that little detailed work has addressed this foundational problem in the ESL area, some relevant work has been done in the more general area of curriculum theory (see, e.g. Schwab 1970, 1971, 1973, 1983), and in that of science education (e.g. Roberts 1980). Schwab's then-radical view of the theory-practice relationship is expressed in the claim that:

Theory, by its very character, does not and cannot take account of all the matters which are crucial to questions of what, who, and how to teach; that is, theories cannot be applied, as principles, to the solution of problems concerning what to do with or for real individuals, small groups, or real institutions located in time and space - the subjects and clients of schooling and schools.

$(1970$, p. 2)

Schwab proposes a solution to the incompatibility of theory and classroom practice that involves diverting attention in matters of practice away from theory and towards three "modes": the practical, or the mode of decision-making in context which requires active deliberation (rather than action following strict theoretical principle); the quasipractical, the mode in which deliberation is concentrated upon identifying the significant variables which must be taken into account before action is taken, and the eclectic, the mode in which practitioners actively identify those parts of different theories that are useful and appropriate for the solution of practical problems (Schwab 1970, pp. 3-5; 12-14). 
The central idea in the context of which Schwab elaborates these distinctions and categories is that "the practical is always marked by particularity, the theoretical by generality" (1971, p. 495). It is in cultivating in practitioners the "art of the practical" and the "art of the eclectic," rather than theoretical knowledge per se, according to Schwab, that educators will best succeed in designing curriculum and instruction. He argues persuasively that theoretical and practical thinking are of essentially different kinds.

Roberts (1980) has interpreted the views of Schwab within the context of science education. In agreement with Schwab, Roberts emphasizes that theoretical knowledge comes in the form of general abstractions of particularities from concrete instances (p. 67). According to Roberts, a theory of science education is a logical impossibility, since theories, by their nature, involve close comparison of different but equally plausible explanations, whereas teachers, on any given occasion, must take one well-motivated course of action. In this view, researchers and teachers actually "do" quite different things: whereas the former are necessarily constrained to see things through particular theoretical "lenses" and in terms of their internal consistency, the latter are not constrained in this way and must think in terms of "practical ethics," in terms of potential instructional and student outcomes which cannot be referenced to research norms (Roberts 1980, pp. 67-68).

If the above arguments are valid, what they mean for ESL is that no single theory of language or of communication is likely to provide a secure direct basis for practice. What is needed in addition to such theories (and altogether independently of them), is active deliberation and eclectic choice about what will fit the needs of particular groups of students in unique educational settings.

While a direct theory-practice relationship in ESL might seem obviously inappropriate in some cases (e.g. transformational grammar), in the case of theories which have been specifically designed with practice in mind and which include claims about the nature of communication, or which relate more directly to the organization and structure of ESL curricula, such a relationship seems more appropriate. In both these latter cases, cases which can be exemplified, respectively, by communicative competence theory (as described, for instance, by Savignon 1983) or by notional-functional theory (Wilkins 1976; van Ek 1977; Finocchiaro \& Brumfit 1983), there lies a more deceptive temptation to try to interpret theoretical pronouncements or theoreticallybased categories directly into practice. But it is important to note that these two theories, although they appear to be highly relevant for teaching practice, are examples of exactly those kinds of theories which both Schwab and Roberts argue to be abstract generalizations that are 
insensitive to particular attributes and particular educational contexts. According to these views, it would be erroneous to suppose, for instance, in the case of communicative competence theory, that the essential division of competence into "grammatical," "sociolinguistic," "discourse," and "strategic," (following Canale and Swain 1980), leads in and of itself to curricular and instructional decisions.

In light of these mainstream arguments about the relationship between theory and practice, it seems that the relationship between theoretical and practical knowledge in the ESL field, just as in other parallel areas, is likely to be a complex and indirect one. A theory of language or a theory of learning, then, is quite different from a theory of action - indeed, it is the contention of both Schwab and Roberts that a "theory of action" is a contradiction in terms. In general, what matters for practice according to these curriculum theorists is active and reflective deliberation on separate educational occasions about students, contexts, and competing theories. Schwab emphasizes that such deliberation is an "art" and that it involves sensitivity and perception of kinds quite different from those associated with the construction of theories.

\section{The temporary status of ESL theories.}

A second major obstacle faced by those attempting direct translation from theory to practice lies in the ephemeral nature of theories themselves. The question of how theories grow and replace one another was taken up in discussion of Kuhn's theory of scientific revolutions by Kuhn himself and a group of other philosophers of science (see Lakatos \& Musgrave 1970; Kuhn 1970). It is apparent from these exchanges that although most philosophers share the idea that growth in scientific knowledge is essentially "revolutionary" in nature, they differ in their views about exactly how replacive changes take place. It was Kuhn's (more conservative) view that the job of scientists is to work and conduct tests within the context of established theories and associated research paradigms - in his words "the scientist must premise current theory as the rules of his game" and must attempt to solve "puzzles" $(1970$, p.4). It was Popper's view, on the other hand, that Kuhn's definition of this "normal" scientific work of researchers was neither true to the history of science nor to the real nature of research, and he claimed that Kuhn in effect supported the idea of theories as "ruling dogmas". Popper's more radical description of theoretical enterprises was that they were "essentially critical", and that theory became meaningless when divorced from the process of critical comparison among theories undertaken with the objective of overthrowing one with another (Popper in Lakatos \& Musgrave, pp. 52-58). 
Whichever of these two versions of theoretical replacement is considered more persuasive, the central point is that both share the perspective that theories are temporary interpretations of reality. In applying this to ESL theory and practice, the views serve to remind us of the continual process of replacement that has occurred quite rapidly in our own field from audio-lingual to cognitive code, and to communicative paradigms. This continuing process is evident now in the form of critical questioning of the paradigm of communicative competence such as that of Swan (1985) who, using some of the terminology characteristic of the dialogue between Kuhn and Popper, vilified communicative competence theory for its status as "dogma," a status which makes the so-called "communicative revolution ... little different from its predecessors in the language teaching field" $(1985, \mathrm{p}$. 2). It can be concluded, then, that a second major reason for pursuing what Schwab called the "art" of practical decisionmaking lies in the ultimate fallibility and expendability of all theories. There is an inherent danger that strong reliance on any singular theory such as that of communicative competence, since it is certainly replaceable, is likely to lead down a path of dogmatism rather than to the encouragement of practical decisions based upon a broad inclusion of all factors relevant to particular groups of students in particular educational settings.

\section{The hypothetical status of theoretical constructs.}

It is an unfortunate fact that after many years of studying human behaviour and cognition we still know little in detail about what goes on in the "black box", to use a familiar metaphor for the mind (or, indeed, for the classroom; see Long 1983). Despite intricate experimental procedures and complex artificial intelligence modelling, we still have no clear answers within the area of language research to questions about what kinds of mental representations underlie linguistic performance. It is not clear, for instance, whether mental representations are coded in visual, auditory, or in some other symbolic form, or whether or not there are significant individual differences in such representations. Researchers and theorists are thus often forced into making guesses about mental functioning in the form of "constructs." Sometimes such constructs (which are of a hypothetical nature themselves) come to light in the form of binary distinctions (for example "competence" vs. "performance") and sometimes they come in more monolithic form.

In the realm of ESL theory and practice, one recent dichotomy that appears to have attracted a great deal of attention and credibility within the field has been that proposed by Krashen (e.g. Krashen 1982) between "acquisition" and "learning." Briefly, it has been Krashen's position that 
adults develop second language competence in two ways; first, by way of subconscious processes (acquisition) and, second, by way of conscious processes (learning). This superficially attractive and intuitively appealing division lies behind Krashen's "monitor model," in the context of which many claims have been made about the differences between adult and child second language learning (for example, that in adults, the conscious monitoring associated with "learning" is in other than ideal circumstances disadvantageous when compared to children's unconscious acquisition). As critiques by both McLaughlin (1978) and Gregg (1984) emphasize, however, any hard and fast distinction such as that which Krashen makes between "conscious" and "subconscious" processes in developing second language competence can be readily falsified. It is clear from observations of both children and adults, for example, that rules which are at first a matter for conscious appraisal can later become relegated to subconscious levels of processing, and that aspects of language first "acquired" can later be consciously appraised (see, in particular, Gregg 1984, p. 82); acquisition and learning are simply not mutually exclusive in the way Krashen's model suggests. The central point here is that distinctions and constructs such as Krashen's - while on initial encounter may seem intuitively appealing - on closer examination often lack substance. Certainly, uncritical admission of such models in deliberation about curriculum and practice would be dangerous.

A good example of a singular construct which is popular but problematic is that of schema in research into cross-cultural reading processes (see e.g. Piper 1985). The problem with schemata is that they can only be defined by way of circularity with the phenomena they purport to "explain." A schema is a structure of mental expectations of some kind, but there are no upper or lower bounds on what such a structure may contain and thus almost anything one might think about - ranging, say, from expectations about waiters and food in restaurants to those about morality or God can be labelled a schema; there is simply no reliable and independent means by which to establish the status of such mental structures. While such constructs like schema, then, may serve reasonably well within a limited research paradigm, if they are understood to be anything more than conventional and heuristically useful tools for use in the absence of secure information about cognitive processes, or if their fundamental circularity remains unrecognized, they are likely to lead to trivial observations which provide information that is of little or no use for practice. The problem with frameworks such as schema-theory is that they can be invoked to explain almost any set of data (on this point, see also Thorndyke and Hayes-Roth 1979; Tuinman 1980). While they may stimulate further exploration by other researchers, when it comes to deliberation about practice, hypothetical constructs - either of the dicho- 
tomous or of the unitary variety - will most sensibly be approached with a healthy skepticism.

\section{The multiple interpretability of theory and research.}

There are two sides to the problem of multiple interpretability. First, there is the problem of the alternative ways in which many theoretical claims can be expressed, a problem sometimes resulting in a plethora of formulations from which it is difficult to make a choice. Second, given some research data analyzed with appropriate and reliable statistical measures, there is sometimes a problem deciding what implications are to be made.

The first kind of variation can be illustrated by way of a number of examples in the area of language theory. The problem gained notoriety some years ago within the context of discussions about transformationalgenerative grammars where the presence of what Chomsky referred to as "notional variance" became apparent. One only need compare any two standard transformational-grammatical texts to realize that various equivalent formulations are possible. While it is the case that the presence of such variants is often more "annoying" than descriptively significant, there are also occasions - especially when it comes to applying linguistic descriptions - when the problem is more severe. The matter was summarized by Lawler and Selinker as follows:

Given the recent chaotic trends among theoreticians of generative grammar, one is led to wonder whether those rules which are the rules will ever be made available, even to the sophisticated reader ...(W)e often allow ourselves to forget that rules are not matters of fact, but theoretical constructs more or less supported by facts.

(Lawler and Selinker 1971, p. 31)

Any ESL teacher who has attempted to select from the array of alternative formulations of English grammar currently available will be well aware of the difficulties. An especially good example of indeterminacy in the area of second language teaching is to be found in the different categorizations and interpretations of language functions prevalent among different authors. For example, in addition to those of Halliday (1973), there are within the framework of notional-functional models those of Wilkins (1976), van Ek (1980), and Finocchiaro (1983) (see Finocchiaro \& Brumfit 1983, pp. 61-66). Yet another candidate for inclusion is Tough's (1977) categorization based on the work of Vygotksy and Luria as well as Halliday.

An illustration of the second problem - that of the multiple interpretability of research results - can be illustrated, once again, by way of reference to the research findings of Piper (1985). Accepting for the 
moment the validity of the schema-theoretic constructs as the starting point for this study (although it has been argued above that such validity is questionable), other problems of interpretation yet remain. A central finding in this research was that adult Vietnamese ESL learners recalled stories written in English which were varied for content and rhetorical structure in the following order: most accurately processed was a story containing Vietnamese content together with typical Vietnamese rhetorical structure, next best processed were two crossed versions (i.e. a story with Vietnamese content and western structure and one with western content and Vietnamese structure), and least successfully processed was a version of the story containing western content and rhetoric. As Piper (1984), indicated, however, several possible interpretations for practice in ESL reading instruction were consistent with these results. These interpretations were as follows:

1. we could immerse students in second-cultural material in the hope that they would develop new western-based narrative schemata by themselves,

2. we could develop idealized sequences of reading activities that start with translations of stories taken from the literature of students' first-cultures, later moving them through a sequence much like that contained in the study treatments towards materials containing second-cultural content and rhetorical form,

3 . we could develop programmes in which a direct and overt comparison is made between first- and second-cultural narratives: that is, we could introduce "contrastive rhetoric" into the classroom, following Kaplan (1966),

4. we could attempt to develop curriculum materials which aim to develop fundamental thinking skills which underlie and are characteristic of English prose - for example, exercises on causal, temporal and other propositional and logical relationships typical of English - in the hope that these will provide the necessary conceptual basis for reading narrative in ESL.

Any one of these possibilities might be considered appropriate pedagogical practice or, to make matters even more complicated, any of several possible ordered (or un-ordered) combinations of two, three, or all four of them might also be well-motivated. The point is that the research itself, although specifically directed towards elucidation of ESL reading, does not, in and of itself provide any direct clues for translation into practice. For this second reason, then, it is only through active deliberation in context that such a matter can be resolved. Such deliberation could itself depend upon such wide-ranging criteria as, for example, the educational background of students, availability of materials, or the homogeneity of 
cultural representation in any given ESL class. The problems of multipleinterpretability provide yet further seemingly intractable difficulties for the direct interpretation of theories and research for practice.

\section{DISCUSSION: THE ACT OF THE ECLECTIC}

It might seem from the above review that the obstacles to sound practical decision-making are insuperable. On the contrary, however, the central objective has been only to identify some of the issues which should be acknowledged in practical decision-making. Schwab's idea that practical decisions necessarily involve "art" and, in particular, the "art of the eclectic," promises us a way of avoiding impasses in relating theory to practice in ESL. But before concluding in favour of some sort of informed eclecticism, some possible ambiguities in interpreting the term "eclecticism" should be mentioned.

There are of course several ways in which the term "eclecticism" can be understood. The first and most obvious interpretation is that eclecticism in classroom practice means that teachers can choose an array of "equally believable" ideas from researchers and theorists since "none of them is superior to any other." Another not much less skeptical version of the same general argument may be expressed informally as follows: "I know some theories may be better than others - but there are so many that I have no idea which is the best and, in any case, if I randomly select from materials and teaching ideas based on a number of different ideas, my students are sure to benefit." One reason why neither of these approaches to eclectic choice is acceptable, however, lies in the risk each entails that resulting practical decisions will embody many actual contradictions. It is surely not rational, for example, to hold at one and the same time that students learn ESL principally through processes of imitation and through processes of rule-governed creativity. Any well-principled eclecticism must therefore avoid the logical pitfall of including positions which are contradictory to each other and will involve choices founded in a preference for one particular approach to learning if it is to remain consistent.

If these forms of eclecticism can be considered "weak," then, what constitutes a stronger and more productive eclectic approach? The answer lies, first, in rejecting the form of random eclecticism mentioned above in favour of making classroom choices which are defensible in terms of their consistency with theory and research; second, in the realization that such consistency can be established only by way of valid description of what goes on in classroom teaching and learning contexts; and third, in recognizing and being aware of the complexity of the challenges outlined above 
and of the dangers of dogmatic reliance on currently fashionable theories. In the end, while in one sense the tasks of theorists and practitioners are (as indicated by Schwab and Roberts) essentially different, in another sense they are very similar. They are similar in that teaching that is truly sensitive to students itself requires constant everyday research and testing by teachers within the flexible, dynamic, and pragmatic contexts of classrooms. The habitual distinction between theory and practice can be neutralized if they are viewed as aspects of one process - a dynamic process in which practice validates or invalidates theory and research and in which the teacher's own role is in part that of classroom researcher. Rather than submission to random choice, then, Schwab's "art of the eclectic" in ESL can be viewed most positively as involving teachers in making and testing hypotheses in the classroom, hypotheses based upon ideas which, although they are ultimately replaceable, are at least consistent with each other and appealing in the context of teachers' special knowledge about their students. In this way, the necessarily indirect relationship between theory and practice can best be viewed from the practitioner's perspective as an essentially active and recursive one - as a relationship which demands constant alternation between classroom observations and theoretical insights. It is within this interactive relationship, a relationship in which theory and practice inform each other, that the art of the eclectic in the field of ESL finds its most principled basis.

\section{REFERENCES}

Canale, M. \& Swain, M. (1980). Theoretical bases of communicative approaches to second language teaching and testing. Applied Linguistics, 1, $1-47$.

Finocchiaro, M. \& Brumfit, C. (1983). The Functional-Notional Approach: From Theory to Practice. New York: Oxford University Press.

Gregg, K. R. (1984). Krashen's monitor and Occam's Razor. Applied Linguistics, $5,79-100$.

Halliday, M. A. K. (1973). Explorations in the Functions of Language. London: Edward Arnold.

Kaplan, R. (1966). Cultural thought patterns in intercultural education. Language Learning, 16, 1-20.

Krashen, S. D. (1982). Principles and Practice in Second Language Acquisition. Oxford: Pergamon Press.

Kuhn, T.S. (1970). The Structure of Scientific Revolutions. Chicago: The University of Chicago Press.

Lakatos, I. \& Musgrave, A. (Eds.). (1970). Criticism and the Growth of Knowledge. Cambridge: Cambridge University Press.

Lawler, J. \& Selinker, L. (1971). On paradoxes, rules, and research in secondlanguage learning. Language Learning, 21, 27-42. 
Long, M. (1983). Inside the "black box": Methodological issues in classroom research on language learning. In Seliger, H.W. \& M. H. Long (Eds.). Classroom Oriented Research in Second Language Acquisition (pp. 3-35). Rowley, Mass.: Newbury House.

McLaughlin, B. (1978). The monitor model: some methodological considerations. Language Learning, 28, 309-332.

Piper, D. (1984). Culture-specific reasoning patterns and their relation to learning to read and write in ESL. Paper presented to the Annual Language Arts Conference, University of Calgary.

Piper, D. (1985). Formal vs. content schemata in the reading of adult Vietnamese students of English as a second language. Reading-Canada-Lecture, 3, 187-197.

Roberts, D. A. (1980). Theory, curriculum development, and the unique events of practice. In H. Munby, G. Orpwood \& T. Russell (Eds.). Seeing Curriculum in a New Light: Essays from Science Education (pp. 65-87)., Toronto: OISE Press.

Savignon, S. J. (1983). Communicative Competence: Theory and Classroom Practice. Reading, Mass.: Addison-Wesley.

Schwab, J. (1970). The Practical: A Language for Curriculum. Washington: National Education Association.

Schwab, J. (1971). The practical: Arts of the eclectic. School Review, 79, 493-542.

Schwab, J. (1973). The practical 3: Translation into curriculum. School Review, $81,501-522$.

Schwab, J. (1983). The practical 4: Something for curriculum professors to do. Curriculum Inquiry, 13, 239-265.

Swan, M. (1985). A critical look at the communicative approach. ELT Journal, 39, 2-12.

Thorndyke, P. W. \& Hayes-Roth, B. (1979). The use of schemata in the acquisition and transfer of knowledge. Cognitive Psychology, 11, 82-106.

Tough, J. (1977). The Development of Meaning. London: George Allen \& Unwin. Tuinman, J. J. (1980). The schema schemers. Journal of Reading, 23, 414-419. van Ek, Jan A. (1977). The Threshold Level for Modern Language Learning in Schools. London: Longman.

van Ek, Jan. A. (1980). Threshold Level English. Oxford: Pergamon Press. Wilkins, D. A. (1976). Notional Syllabuses. Oxford: Oxford University Press.

\section{THE AUTHOR}

David Piper is Assistant Professor and ESL Coordinator in the Department of Curriculum and Instruction, University of Calgary. He studied English, Linguistics, and Education at the universities of Cambridge, Reading, and London in the U.K., and took his Ph.D. in Linguistics and Educational Psychology at the University of Alberta, where he was a Killam Scholar. He has taught ESL/EFL at a variety of levels, ranging from grade 6 EFL courses in the U.K. to ESL courses for Canada Manpower, courses in advanced ESL Composition, and reception classes for Vietnamese refugees in Canada. Following periods of teaching at the universities of B.C. and Regina, Dr. Piper has, since September 1983 , been coordinator of the ESL teacher-training programme at the University of Calgary. 